\title{
Erratum to: A review of recent research into aerodynamics of sport projectiles
}

John Eric Goff

Published online: 26 May 2013

(C) International Sports Engineering Association 2013

\section{Erratum to: Sports Eng}

DOI 10.1007/s12283-013-0117-z

In the original version, the buoyant force on a baseball has been incorrectly published as $1.5 \%$ of the ball's weight (found between Eqs. (6) and (7)).

The correct buoyant force is $0.15 \%$ of the ball's weight.

The online version of the original article can be found under doi:10.1007/s12283-013-0117-z.

J. E. Goff $(\bowtie)$

Department of Physics, Lynchburg College, 1501 Lakeside

Drive, Lynchburg, VA 24501-3113, USA

e-mail: goff@1ynchburg.edu 